\title{
Laser-Induced Forward Transfer: An Approach to Single-Step Polymer Microsensor Fabrication
}

\author{
V. Dinca ${ }^{1, *}$, R. Fardel ${ }^{2,3}{ }^{\dagger}$, J. Shaw-Stewartt ${ }^{2,3}$, F. Di Pietrantonio ${ }^{4}$, D. Cannatà ${ }^{4}$, \\ M. Benetti ${ }^{4}$, E. Verona ${ }^{4}$, A. Palla-Papavlu ${ }^{1}$, M. Dinescu ${ }^{1}$, and T. Lippert ${ }^{3}$ \\ ${ }^{1}$ NILPRP, National Institute for Lasers, Plasma and Radiation Physics, 409, Atomistilor, Romania \\ ${ }^{2}$ EMPA, Swiss Federal Laboratories for Materials Testing and Research, Laboratory for Functional Polymers, \\ Überlandstrasse 129, 8600 Dübendorf, Switzerland \\ ${ }^{3}$ Paul Scherrer Institut, General Energy Research Department, 5232 VIIligen PSI, Switzerland \\ 4 "O.M.Corbino" Insitute of Acoustics, Italian National Research Council-CNR, \\ via del Fosso del Cavaliere 100, 00133 Rome, Italy
}

(Received: 5 June 2009. Accepted: 30 November 2009)

\begin{abstract}
Laser-induced forward transfer (LIFT) using a triazene polymer as dynamic release layer was used for the transfer of polyethyleneimine (PEI) pixels for microsensors applications. A XeCl laser was used to transfer the PEI pixels from a thin film coated onto the trlazene layer. The PEI films were either in direct contact with the recelver or a gap was maintained between the donor film and the receiver. An optimization of the process was carried out by changing the laser fluences, the ratio between the thickness of the PEI and of the triazene layer, and the transfer distance. Welldefined, regular PEl pixels were obtained on the recelver. The morphology of the patterns was characterized using optical microscopy and scanning electron microscopy (SEM). The transler onto surface acoustic wave (SAW) devices suggests that LIFT is a promising technlque for the fabrication of microsensors with polymers as active layer.
\end{abstract}

Keywords: Laser-Induced Forward Transfer, PEI, SAW.

\section{INTRODUCTION}

The precise positioning of polymeric compounds is an essential part for their use in technological applications. The development of laser techniques for transferring different materials in a controlled and direct manner on solid surfaces has attracted much attention during the last years for various applications. ${ }^{1-7}$ For example, a rapid deposition and patterning by Laser Induced Forward Transfer (LIFT) in a clean environment of high $T_{\mathrm{v}}$ superconducting thin films has applicability for micro- and opto-clectronic applications. ${ }^{8}$ Also, the possibility of transferring liquids through LIFT revealed that this technique could be applied to the deposition of organic and biological compounds in solution, ${ }^{9-12}$ and it was demonstrated that LIFT could be used to successfully transfer proteins ${ }^{10-12}$ or DNA. ${ }^{13}$

\footnotetext{
"Corresponding nuthor; E-mail: dincavalentinn @yahoo,com

tPrinceton University, Department of Mechanical and Aerospace Engineering Engineering Quadrangle, Princeton, NJ 08544, USA.
}

LIFT assisted by a releuse layer or by a dynamic release layer (DRL) has already been used for printing micron-sized patterns or features of a wide range of materials in solid or liquid/viscous statc. ${ }^{1+17}$ For example, LIFT and triazene polymers as release layer were successfully applied to transfer sensitive materials such as organic light emilting diode pixels, ${ }^{14}$ living eells ${ }^{15}$ and nanocrystal quantum dots ${ }^{16}$ as well as for transferring pixels from thin metallic films. ${ }^{17}$ The trunsfer of polymer patterns has an incrensed interest due to their upplication in chemical or bio-sensors. One attractive polymer in this field is polyethyleneimine (PEI) which has a variety of applications, e.g., chemical sensing, due to its reactivity with hydrazine based compounds, but also in the biomedical lield, due (t) its cupability as transfection enhancer.

In this study, the laser printing of PEl using a dynamic release layer is analyzed, where the optimal parameters for obtaining well defined pixels of a transferred polymer are established. Preliminary studics on the characteristics of 
PEI pixels obtained by LIFT for microfabrication sensors are also described.

\section{EXPERIMENTAL DETAILS}

The transfer was achieved using a single pulse from a $\mathrm{XeCl}$ excimer laser (Compex, Lambda Physik, $308 \mathrm{~nm}$, $30 \mathrm{~ns}$ ). A square mask with an aperture of $2 \mathrm{~mm}$ was applied to utilise a homogeneous part of the beam, which was focused by a lens onto the backside of the donor film with a demagnification of 4, giving a spot size of $500 \mu \mathrm{m}$. The donor and the receiver substrates were placed perpendicular to the beam in close contact $(<1 \mu \mathrm{m})$ or with a gap defined by a spacer (up to $100 \mu \mathrm{m}$ ) on a motorized translation stage.

The computer-controlled system allows creating a matrix of pixels for each sample, where the pulse energy is varied. The profile of the transferred patterns was measured by profilometry (Ambios XP-1 profilometer). The images were taken by an optical microscope (Zeiss Axioplan) coupled with a digital camera (Leica DC500) and/or by a scanning electron microscopy (SEM). A pixel matrix was created from the polymers film by varying the fluence for each line to establish the optimum parameters for a clean transfer. All transfer experiments were performed in air. The transfer experiments were performed at low (up to $400 \mathrm{~mJ} \mathrm{~cm}^{-2}$ ) and high fluences (up to $800 \mathrm{~mJ} \mathrm{~cm}^{-2}$ ) to investigate the influence of the fluence range on the transfer. An additional triazene polymer layer, acting as dynamic release layer or sacrificial layer, was introduced to avoid laser induced degradation of the PEI.

The multilayer donor films were prepared by coating successively fused silica substrates with the triazene polymer and the transfer material, i.e., PEI. Films of the triazene polymer were prepared by spin conting from solutions of the triazene polymer in chlorobenzene/cyclohexanone $(1: 1, w / w)$ with final film thicknesses of 0 to $250 \mathrm{~nm}$. Polyethylenimine (PEI, 1.5 to $5 \mathrm{wt} \%$ in ethanol) was spin-coated on top of the triazene layer and thin films with thicknesses from $100 \mathrm{~nm}$ to $300 \mathrm{~nm}$ were obtained. The exact thickness of the films was determined by a surface profiler (Dektak 8000). The depth of the ablated craters from the target, as well as the height of each transferred pixel was measured with the surface profiler.

The receiver substrates were glass plates cleaned by sonication and SAW devices fabricated in two different configurations, i.e., resonator and delay line. Optical microscopy and SEM were used to analyze the morphology of the deposited pixels.

\section{RESULTS AND DISCUSSION}

The transfer of polymer patterns has practical interests, for instance as sensitive layer on various devices for sensors applications. The influence of the laser fluence in relation with the thickness of the target material on the transfer is discussed first. Constant layer thicknesses of $150 \mathrm{~nm}$ of PEI on top of a $200 \mathrm{~nm}$ thick triazene polymer layer were selected for the experiments related to the influence of the laser fluence on the transferred pixcls. All applied fluences were investigated at least three times. The observation from optical microscopy images reveal that a clean transfer can be achieved for a quite narrow window of fluences. An overview of the donor (up) and receiver substrates (down) after the transfer is presented in Figure 1 for fluence values for which the transfer is clenn and well defined. Transfer without any type of debris or splashes around the pixels was is achieved between $590 \mathrm{mJcm}^{-2}$ and $800 \mathrm{mJcm}^{-2}$. In the case of high fluence, the material is removed from the irradiated spot (Fig. 1(a)), and the material is transferred as polymer pixel that can be found intact on the receiver (Fig. 1(c)). By decreasing the laser fluence $\left(590 \mathrm{mJcm}^{-2}\right)$, the delamination is still observed on the donor surface, and the square edges are clearly cutout (Fig. 1(b)), while the pixels keep a regular shape, but with a different surface aspect and with missing part inside the pixel (Fig. 1(d)). The transferred materials changes in aspect and even more non-continuous regions appear inside the pixels (Fig. 2) for fluence values in the range of 450-300 mJ cm-2.

By decreasing the fluence to values below $300 \mathrm{~mJ} \mathrm{~cm}^{-2}$, the transfer is becoming less regular (Fig. 3 left column) and at very low values, bellow $200 \mathrm{mJcm}^{-2}$, no transfer occurs anymorc (Fig, 3 right column). This is very different to the transfer metals or liquids where much lower fluences are required. $8.9,14$

The thickness of the triazene polymer is important, because together with the applied fluence, it determines the amount of released gas and the remaining thickness of non-ablated triazene polymer. ${ }^{14,17}$ The transfer of PEI was therefore investigated with different triazene polymer layer thicknesses (from 0 to $250 \mathrm{~nm}$ ) while keeping the $\mathrm{PEI}$ layer thickness unchanged. For all the samples, the fluence al which a complete detachment of the polymer pixel occurs was determined by visual inspection of the donor substrates. These detaching fluences depend strongly on the triazene polymer layer thickness. ${ }^{17}$

A clean transfer was only achieved with a layer of tijazene polymer which is thicker than the thickness of PEI whereas all thinner triazene polymer films did not yield any satisfactory results. Some examples can be seen in Figure 3. The arrow indicates the decrease of the laser fluence (from maxim value of $300 \mathrm{mJcm}^{-2}$ to minim value of $100 \mathrm{~mJ} \mathrm{~cm}^{-2}$ ). One important effect is clearly visible: for thinner layers of TP and thicker PEI films, the amount of triazene polymer becomes too small to provide the force needed to overcome the mechanical resistance of the polymer, i.e., to "cut" a PEI pixel from the film. The detaching 

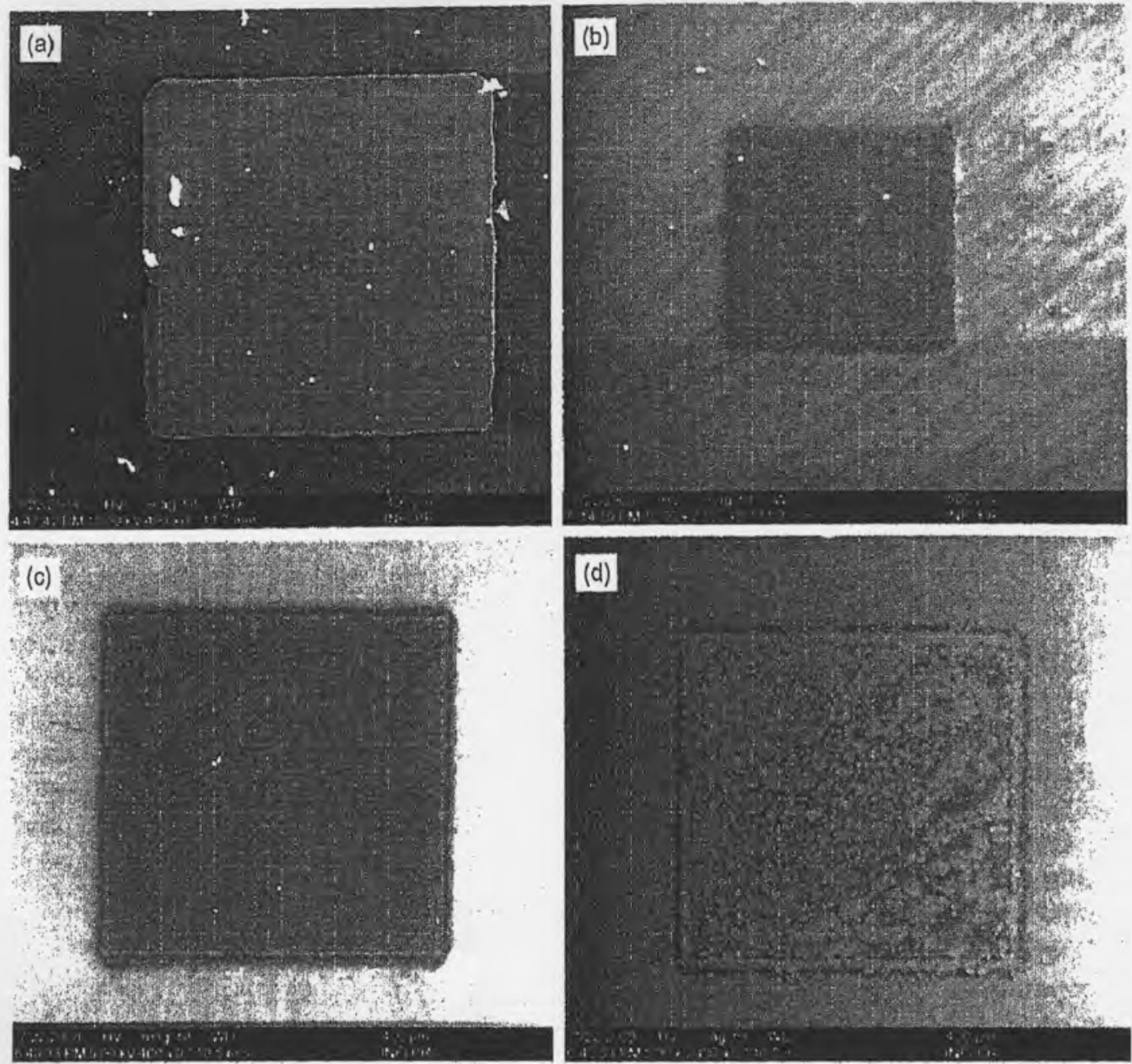

Fig. 1. SIBM images of the irradiated spot for fluences of $800 \mathrm{~mJ} \mathrm{~cm}^{-2}$ (a) and $675 \mathrm{~mJ} \mathrm{~cm}{ }^{-2}$ (b) and the eurresponding Ptil pixels (c and d) transferred on glass.

is therefore not complete and a deformation of the polymer induced by the pressure from the TP decomposition is observed. One part of the polymers sticks on the receiving substrates (Fig. 3 bottom) but the major part of the pixel remains on the target due to the limited available mechanical force (pressure). Some edges consist of teared out film that do not adhere to the receiver substrate. In these cases the pixel does not break into pieces but the pixel edges are folded during the transfer.

When the same thickness of the triazene polymer and PEI was used, an improvement of the surface of the pixel is observed but better results are obtained by increasing the thickness of the triazene polymer which is larger than the thickness of the PEI layer.

Homogeneous deposits with well-defined edges are obtained as well in this case for high fluences (700-800 mJ c m${ }^{-2}$ ), (Fig. 4(a)) while for lower fluences, particles or debris appear around the deposits. The debris observed for the pixels obtained at $550 \mathrm{~mJ} \mathrm{~cm}^{-2}$ is not easy to remove with a soft air blow as shown in Figure 4(b). An optimal transfer can be achieved by using a layer of the triazene polymer that exceeds the thickness of the polymeric layer, whereas thimner films reçuire lower fluences for the transfer.

Another important observation is related to the fact that the receiving substrates should he in elose eontact for a controlled transfer. The optical microseopy images reveal that for uny successfully used belore conditions, no well defined pixels were obtained for the transfer across a gap. This can be explained by the fact that the shockwave formed is reflected when it reaches the receiver surface, and destroys the material.

Initial tests for transferring polymers on transducers have also been performed.

The main parameters that have to be eontrolled for the successful transfer on the active area of the sensor are: the thickness, the homogeneity and the area of the film coating. It is eriticel to obtain a high homogeneity of the coating in order to minimize seattering and diffraction of the SAWs. In addition to the coating thicknoss that affects the SAW phase velocity and the insertion losses, it is important that the impact of the polymer should not destroy the interdigital transducers (IDTs) of the device. 

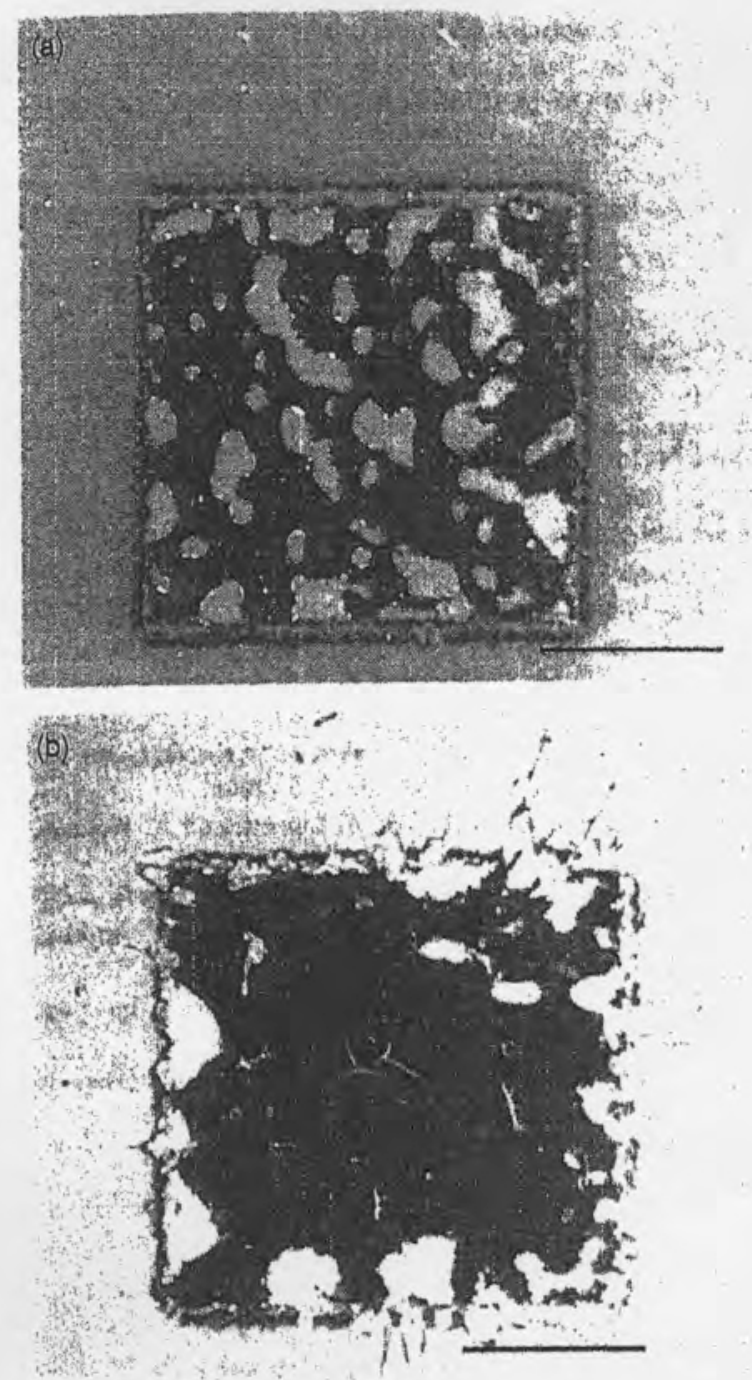

Fig. 2. SEM images of PFĩ pixels on glass obtained with fluences of (n) $450 \mathrm{~mJ} \mathrm{~cm}-2$ and (b) $300 \mathrm{~mJ} \mathrm{~cm}^{-2}$. The senle bar is $200 \mu \mathrm{m}$.

Values corresponding to the insertion losses for two fluences employed lor transfer are shown in Figure 5. The PEI pixel was transferred to specific areas of interest without destroying it (Fig. 5, insertion). It was observed that for high fluences $\left(800 \mathrm{~mJ} \mathrm{~cm}^{-2}\right.$ ) the IDTs are casily destroyed either by the shock wave or by the high velocity impact of the flyer on the IDT surface. For example, for fluences smaller than $700 \mathrm{~mJ} \mathrm{~cm}{ }^{-2}$, rensonable changes in the insertion losses are obtained.

The choice of the sensor polymer layer was guided by the final goal of our LIFT method, which is to transfer pixels of chemoselective polymers for labricuting chemoselective sensors. The transfor of various polymer pixels without altering the properties of the transferred materiuls is critical in order to assess the relevanee of this technique for the microfabrication of sensors. Further investigations will be carried out to determine the sensitivily of the device to hydrazine based compounds and for various gases.

Sensor Letters 8, 436-440, 2010

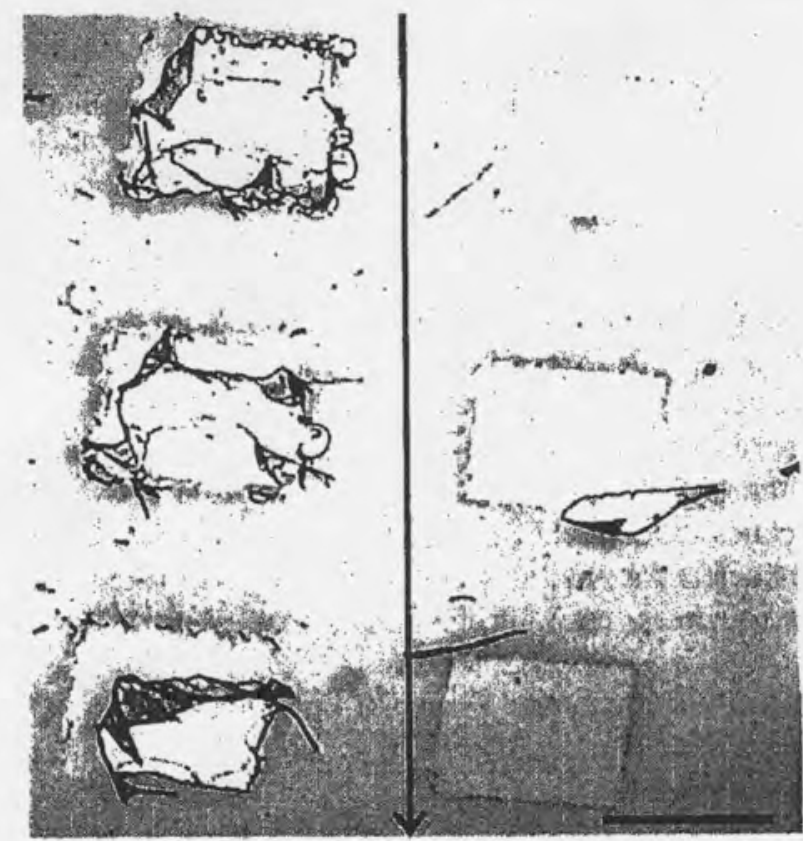

Fig. 3. Optical microscope images of PEI pixels transferred on glass for fluences lower than $300 \mathrm{~mJ} \mathrm{~cm}^{-2}$ (left column) and lower than $200 \mathrm{~mJ} \mathrm{~cm}^{-2}$ (right column), The scnle bar is $500 \mu \mathrm{m}$.
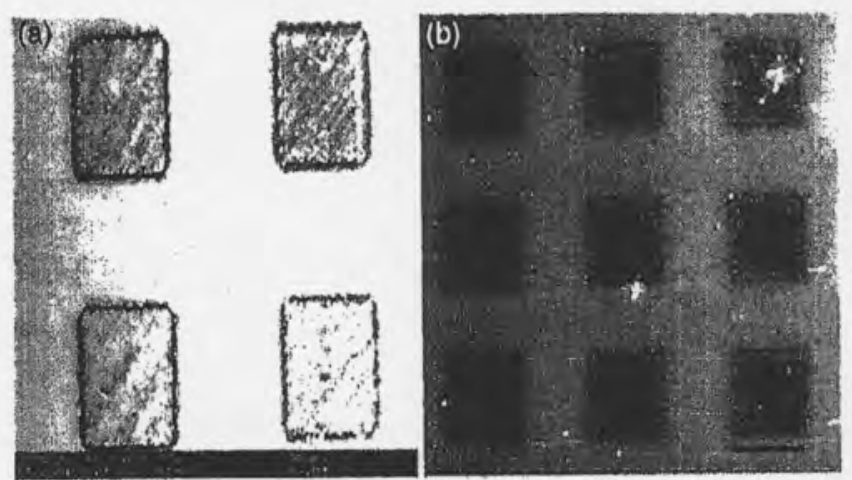

Nig. 4. SEM images of PEI pixels arrny transferred on glass for for fluences of $800 \mathrm{~mJ} \mathrm{~cm}^{-2}$ (a) and $550 \mathrm{~J} \mathrm{~cm}^{-2}$ (b).

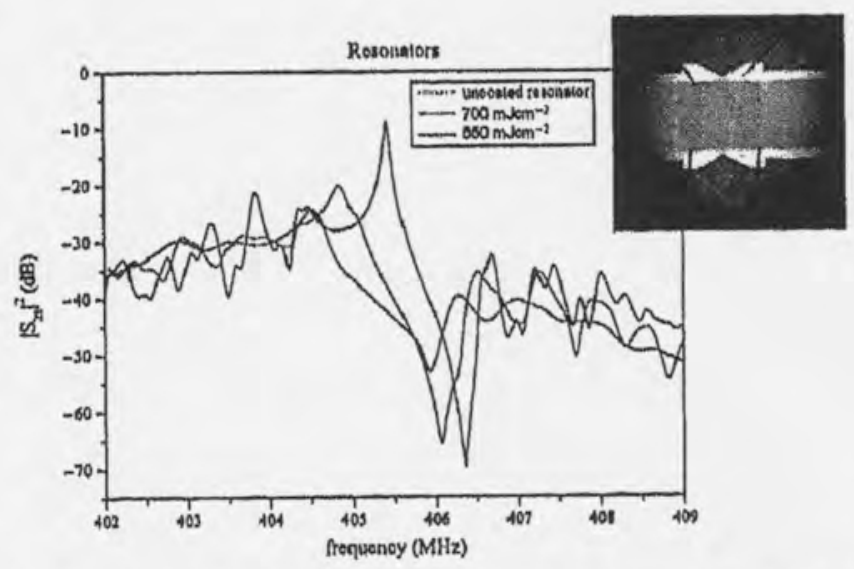

Fig. 5. Changes in insertion losses graph in the cnses of the transfer with two dlifferent fluences and PEI polymer pixels transferred on IDT surface (insertion). 


\section{CONCLUSIONS}

The laser-induced forward transfer is strongly influenced by the process parameters and only a narrow operating window can be applied for a successful transfer. There is a minimal thickness of the dynamic release layer, i.c., the triazene polymer, required to benefit fully of the advantages offered by a dynamic release layer. SEM and optical microscope image analyses on the deposited films show that continuous, hole free pixels are obtained for specific experimental conditions. Both, the laser fluence as well as the total target thickness and the relation between the thicknesses of the PEI to the triazene polymer, are key parameters for obtaining continuous polymer pixels with a low roughness on SAW devices.

Acknowledgments: Financial support from the NATO Science for Peace SfP 982671 program is gratefully acknowledged.

\section{References and Notes}

1. F. J. Adrian, J. Bohandy, B. F. Kim, A. N. Jetle, and P. Thompson, J. Vac. Sci. Teclmol. B 5, 1490 (1987).

2. C. Arnold, P. Serrn, and A. Pique, MRS Bull, 32, 23 (2007).

3. I. Zergioti, S. Mailis, N. Vainos, C. Fotakis, S. Chen, and C. Grigoropoulos, Appl. Surf. Sci. 601, 127 (1998).
4. B. Hopp, T. Smausz, N. Kresz., N. Barna, Zs. Bor, L. Kulozsvári, D. B. Chrisey, Szabó, and A. Nógrádi, Tïssue líng. 11, 1817 (2005),

5. D. Banks, P. Grivns, C. Mills, J. D. Easen, and I. Zergioti, I. Appl. Phys. Letf. 89, 193107 (2006).

6. I. Zergioti, A. Knruiskou, 1). G. Pnpazoglou, C. Fotakis, M. Kapsetaki, and D. Kafetzopoulos, Appl. Phy.s. Lett. 86, 163902 (2005).

7. J. A. Barron, B. R. Ringeisen, H. Kim, B. J. Spargo, and D. B. Chrisey, Thin Soliel Fïlms 45.3-454, 383 (2004).

8. E. Fogarnssy, C. Fuchs, F. Kerherve, G. Hauchecome, and 1. Perribre, J. Mater: Res. 4, 1082 (1989).

9. V. I)inca, M. Farsari, D. Kafetzopoulos, A. Popescu, M. Dinescu, and C. Fotnkis, Thin Solid Fïlms 18, 6.504 (2008).

10. D. B. Chrisey, A. Pique, R. A. McGill, J. S. Horwitz, B. R. Ringeisen, D. M. Bubb, and P. K. Wu, Chem. Rev! 103, 553 (2003).

11. P. Serra, J. M. Fernández:Prndas, F. X. Berthet, M. Colina, J. Elvira, and J. L. Morenzn, Appl. Physs, A: Muter: Sci, Precess. 79, 949 (2004).

12. B. R. Ringeisen, D. B. Chriscy, A. Piqué, H. D. Young, R. Modi, M. Bucaro, J. Jones-Mechan, and B. J. Spargo, Biometterictls 23, 161 (2002).

13. A. Karaiskou, I. Zergioti, C. Fotukis, M. Kapsetaki, and D, Kafetzopoulos, Appl. Surf. Sci. 208-209, 24.5 (2003).

14. R. Fardel, M. Nngel, F. Nuesch, T. Lippert, and A. Wokaun, Appl. Phys. Le'll. 91, 061103 (2007).

15. A. Doraiswamy, R. Naraynn, T. Lippert, and L. Urech, A. Wokaun, M. Nagel, B. Hopp, M. Dinescu, R. Modi, R. Auyeung, and D. Chriscy, Appl. Surf. Sir\%. 2.52, 4743 (2006).

16. J. Xu, J. Liu, D. Cui, M. Gerhold, A. Y. Wnng, M. Nagel, and T. Lippert, Nenetechnolesgy 18, 025403 (2007).

17. R. Fardel, M. Nngel, F. Nuesch, T. Lippert, nud A. Woknun, Appl. Surf. Sci. 254, 1322 (2007). 